\title{
Pilot study of an online training program to increase genetic literacy and communication skills in oncology healthcare professionals discussing $B R C A 1 / 2$ genetic testing with breast and ovarian cancer patients
}

\author{
Bettina Meiser ${ }^{1}\left[0 \cdot\right.$ Paula Woodward ${ }^{2} \cdot$ Margaret Gleeson $^{3} \cdot$ Maira Kentwell $^{4} \cdot$ Helen Mar Fan $^{5} \cdot$ Yoland Antill $^{6,7}$. \\ Phyllis N. Butow ${ }^{8} \cdot$ Frances Boyle $^{9,10} \cdot$ Megan Best $^{11} \cdot$ Natalie Taylor $^{12,13} \cdot$ Katy Bell $^{14} \cdot$ Kathy Tucker $^{15}$
}

Received: 9 March 2021 / Accepted: 30 April 2021 / Published online: 10 May 2021

(c) The Author(s), under exclusive licence to Springer Nature B.V. 2021

\begin{abstract}
The increasing use of genetic testing for BRCA1/2 and other pathogenic variants in the management of women with breast and ovarian cancer necessitates increased genetic literacy in oncology healthcare professionals. This pilot study aimed to evaluate an online training program to increasegenetic literacy and communication skills in Australian oncology healthcare professionals tasked with discussing and coordinating mainstream genetic testing with breast and ovarian cancer patients. A training website with embedded videos was developed. This study assesses the website's acceptability and user-friendliness; suggestions for improvement were also elicited. Oncology healthcare professionals were recruited through relevant professional organisations, invited to the study by email, asked to work through the website and then complete an online questionnaire. Thirty-two oncology healthcare professionals completed the questionnaire after viewing the website. Nearly all participants were satisfied with the information contained in the program (very satisfied: $n=14 / 32,44 \%$, satisfied: $n=17 / 32$, $53 \%$, neither satisfied nor dissatisfied: $\mathrm{n}=1 / 32,3 \%)$ and reported that they had gained new skills $(\mathrm{n}=29 / 32,91 \%)$ and had increased confidence $(n=29 / 31,94 \%)$ in communicating with breast and ovarian cancer patients about genetic testing. More than 93\% (28/30) of participants endorsed the online program as clearly presented, informative, relevant and useful. This pilot study demonstrated high feasibility and acceptability of the training program to increase genetic literacy and communication skills in oncology healthcare professionals discussing genetic testing with breast and ovarian cancer patients. Further evidence from a randomised trial is needed to evaluate effects on changing clinical practice, improving patient outcomes, and cost-effectiveness.
\end{abstract}

Keywords Communication training $\cdot$ Online training $\cdot$ Oncology healthcare professionals $\cdot$ Genetic testing $\cdot$ BRCAl . $B R C A 2 \cdot$ Breast cancer $\cdot$ Ovarian cancer

\section{Introduction}

Germline testing of cancer susceptibility genes refers to testing for specific, high-penetrance pathogenic variants. This includes pathogenic variants in the breast/ovarian cancer genes BRCA1 and BRCA2 (BRCA1/2). Identification of carriers of these variants can save lives because it allows for: (i) identification of affected women who may benefit from targeted treatment options [1-3]; (ii) prevention of other

Bettina Meiser

b.meiser@unsw.edu.au

Extended author information available on the last page of the article primary cancers; and (iii) the opportunity for predictive testing in biological relatives to enable implementation of preventative strategies in those identified as carriers [4-6].

Traditionally, genetic testing for cancer susceptibility and communication of the results have been managed exclusively through genetics-trained specialists at familial cancer clinics. In recent years, there has been a paradigm shift with the provision of genetic counselling and testing increasingly offered by non-genetics trained specialists, often referred to as 'mainstreaming'. This shift in practice benefits patients and their families through potentially increased and faster access to appropriate publicly funded germline genetic testing $[7,8]$. 
Several factors have prompted the adoption of a mainstreaming model of genetic testing. Australian [9] and international guidelines [10] on germline $B R C A 1 / 2$ genetic testing have expanded to include other indications in addition to the classic feature of a strong family history [11, 12], increasing the number of women for whom genetic testing is recommended. These additional indicators include younger age at breast cancer diagnosis, presence of bilateral breast cancer, membership in an ethnic group with a high incidence of founder mutations (for example, Ashkenazi Jewish background), as well as tumour tissue characteristics, in particular triple negative breast cancer (estrogen and progesterone receptor and HER2 negative) [11, 12]. Second, the availability of targeted treatment, poly (ADP-ribose) polymerase (PARP) inhibitor, for platinum-sensitive $B R C A$ -mutated high-grade epithelial ovarian cancer patients [13] means that it is more time-efficient for oncology specialists to request these tests without needing to refer the patient to a specialised genetics clinic. BRCA1/2 testing may also be of assistance in planning surgical therapy for women with breast cancer, whilst receiving neoadjuvant systemic therapy [14]. The falling costs of all types of genetic tests [15] have also contributed to the rapidly increasing number of tests ordered. Finally, in Australia one driver of a shift towards mainstreaming is the recent provision of government (Medicare) funding for germline testing of breast and ovarian cancer predisposition genes, which may be requested by a non-genetics specialist $[13,16]$.

Communicating germline genetic test results can be challenging, in particular, when variants of uncertain significance are found, or when no pathogenic variant is identified to explain a significant and penetrant family history suggestive of an underlying high-risk gene. Healthcare professionals obtaining consent for germline mutation analysis from patients face the challenge of counselling about possible outcomes to ensure informed choice. This requirement and the demands of addressing a shared family risk require skills in genetic literacy and in genetic risk communication.

Numerous overseas studies have shown that non-genetics healthcare professionals, including medical oncologists [17], have insufficient knowledge of genetics, are mostly illprepared to counsel patients regarding germline genetic test results and report unmet educational needs [18-21]. Similarly, a recent Australian needs assessment of medical specialists from diverse medical backgrounds highlights a need for continuing genomic education that is targeted to the speciality [22]. Non-genetics healthcare professionals are often poor at accurate and detailed family history documentation $[8,23]$ and risk communication [24] and reportedly lack adherence to guideline-based practices regarding BRCA1/2 testing [25]. Finally, and possibly most importantly, misinterpretation of test results may result in incorrect management $[19,25]$. Unless specialists receive education and training in genetic literacy and communication skills, their genetic care of individual patients may be unhelpful and possibly even harmful.

Mainstream genetic testing differs from traditional genetic testing because it is treatment-focused-it has the potential to provide a treatment advantage to the individual. As such, most people want testing. In our previous studies in both the breast cancer and ovarian cancer setting, we demonstrated that women unanimously commented that the decision to undergo testing was a "no-brainer" [26-29]. As such, the communication skills required in the context of mainstream testing need to predominately focus on conveying genetic testing results to patients, in contrast to the communication skills required in relation to traditional genetic testing, which encompass tailored counselling to promote informed and shared decision-making regarding whether to have or postpone testing.

Genetic literacy and communications skills are a complementary set of proficiencies: Genetic literacy includes knowing the indications for having particular germline genetic tests and core concepts to understand genetic risk, while communication skills focus on skills for conveying complex and nuanced genetic testing results to patients and family members. Given the rapidly increasing number of genetic tests being offered by oncology healthcare professionals, there is an urgent need for the genetic literacy and communication skills of these professionals to be enhanced to ensure optimal translation of genetic research findings into mainstream healthcare [22, 30, 31]. A meta-analysis [32] and other reviews $[33,34]$ of online training interventions for specialists conclude that such interventions are educationally beneficial and can achieve outcomes similar to those of traditional teaching methods, with studies favouring online instructions compared to traditional methods [32]. Therefore, online training of oncology healthcare professionals seems particularly well suited to achieve the desired advances in genetic literacy and communication skills.

This article describes the development and pilot testing of an online training program to increase genetic literacy and communication skills to convey $B R C A 1 / 2$ genetic testing results in oncology healthcare professionals discussing genetic testing with breast and ovarian cancer patients. The focus of the website was on genetic testing for BRCAl/2 pathogenic variants because of the rarity of pathogenic variants related to breast and/or ovarian cancer predisposition in other genes, and because at the time of the study targeted treatments covered by Medicare funding such as PARP inhibitors were only available for BRCAl/2-mutated platinum-sensitive relapsed high-grade serous epithelial ovarian cancer [1-3]. However, the online training module was always written with the intention of expanding it at a later time to include other genes-not just breast and ovarian cancer genes, but also bowel cancer and other genes. 


\section{Methods}

\section{Development of website content}

The online training program was developed by a multidisciplinary committee, including healthcare professionals with expertise in genetic counselling, clinical genetics and oncology and an expert in healthcare communication. The website is available for viewing at the following URL: https://www. mainstreamgenetictesting.com.au.

The content of the website was based on a previously developed face-to-face workshop training module for oncology healthcare professionals to enable mainstreamed genetic testing [35]. This module in turn was informed by a formerly published mainstreaming training module [7], our previous research findings $[28,36]$, national guidelines regarding who was eligible for testing [9] and expert opinion.

\section{Format of the website}

The website was developed to meet the needs and demands of non-genetics specialist oncology healthcare professionals and to enable access to an online educational tool for use at anytime and anywhere. The website is built on the Word Press platform. It utilises the LearnDash learning management system (LMS) and contains two SCORM 2014-compliant/Tin Canny modules, developed using Articulate Storyline 360 . The website contains two modules. Module 1 provides an introduction to mainstream genetic testing, and Module 2 covers the mainstream genetic testing process.

\section{Embedded videos}

Modules 1 and 2 include a total of eight embedded videos, which are arranged thematically throughout the modules and are between 0:38 and 4:00 min in length. They feature a genetic counsellor, an oncology nurse and a medical oncologist, who are well-known Australian and UK-based experts in BRCAl/2 genetic testing.

\section{Links to resources}

Links to resources are provided to: the national guidelines on BRCA1/2 genetic testing [9]; Medicare Benefits Schedule items to ensure correct ordering of tests $[13,16]$; a list of local familial cancer clinics/genetics services; and a guide to using the Manchester scoring system to assess a patient's eligibility for genetic testing under the Medicare Benefits Schedule, adapted from Evans et al. [37]. Other tools and resources to support mainstream genetic testing were based on the developed face-to-face workshop training module for oncology healthcare professionals to enable mainstreamed genetic testing [35]. These tools and resources included: a flow chart describing the mainstream genetic testing process, a patient consent form template, a genetic test request form template and a sample script to help guide the introduction of mainstream genetic testing to patients. Two patient education brochures are also included: (i) on BRCAl/2 genetic testing in women newly diagnosed with ovarian cancer (developed as part of the previous workshop training [35]), and (ii) on treatment-focused genetic testing for women newly diagnosed with breast cancer [27]. Finally, a fact sheet on life insurance and genetic testing is included.

\section{Content of the website}

\section{Module 1: introduction to mainstream genetic testing}

Module 1 consists of 19 content screens covering: an introduction to mainstream genetic testing of $B R C A 1 / 2$, fundamentals of genetics and an overview of genetic testing. The content screens are followed by reinforcing activities consisting of seven screens with open-ended, true/false questions and multiple-choice items. See Fig. 1 for examples of reinforcing activities. Instructions ask users to check their understanding of the information provided in the module by checking their answers against the summary screens following these reinforcing questions. Module 1 includes two summary screens.

\section{Module 2: the mainstream genetic testing process}

Module 2 consists of 34 content screens covering: tools and resources to support mainstream genetic testing of $B R C A 1 / 2$; assessment that the patient meets the eligibility criteria for Medicare funded genetic testing; introduction to mainstream genetic testing, consenting patients for testing and organising the test; receiving, interpreting and giving genetic test results; referral to the local familial cancer clinic/genetic service; and questions patients are asked during the mainstream genetic testing process. The content screens are once again followed by reinforcing activities consisting of eight screens with questions, followed by three summary screens.

\section{Evaluation of the communication skills and genetic literacy training program}

\section{Participants}

Individuals were deemed eligible to participate if they were oncology healthcare professionals and provided care to oncology patients in Australia, including medical or radiation oncologists, gynae-oncologists, surgeons, and oncology nurses. These professional groups were included because 


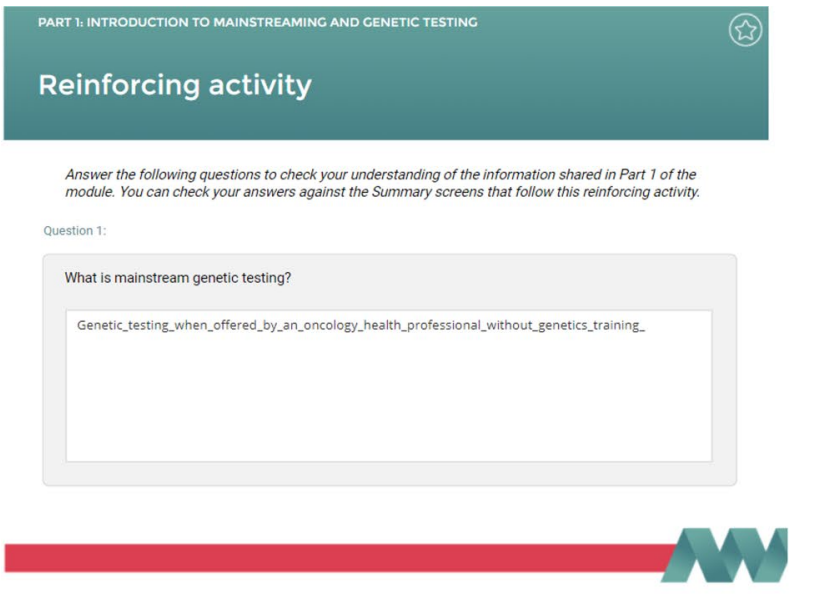

\section{Reinforcing activity}

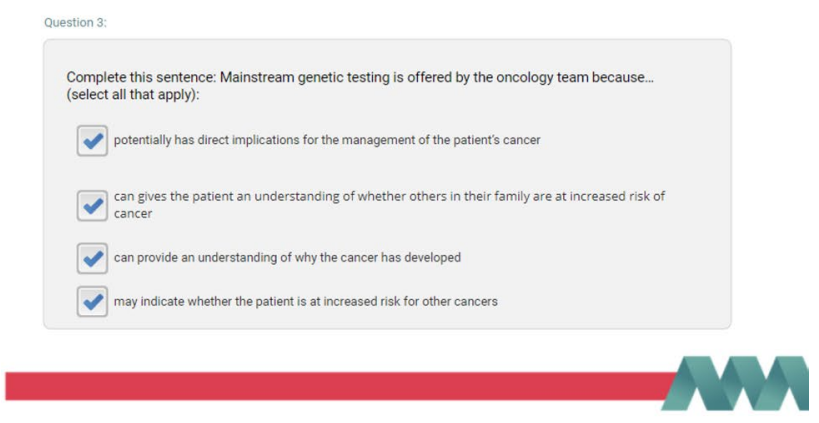

DART L L INTROOUCTTON TO MANSTREAMING AND GENETIC TESTING

Reinforcing activity

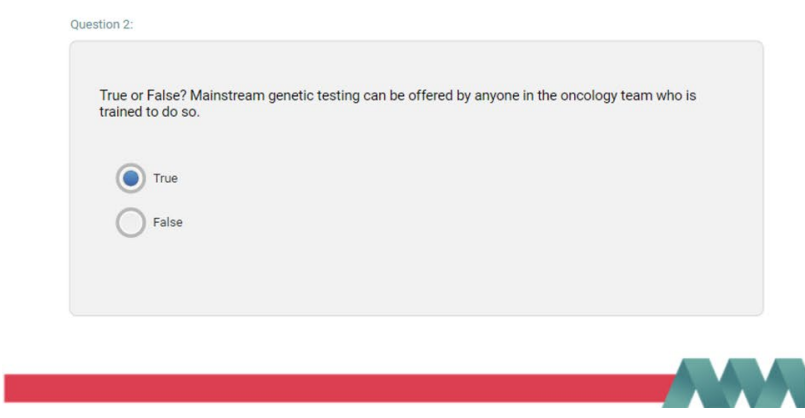

Fig. 1 Examples of reinforcing activities

they were either already discussing genetic and genomic testing with patients or were likely to do so in the future.

\section{Recruitment}

Oncology healthcare professionals were identified through relevant professional organisations: Clinical Oncological Society of Australia, Medical Oncology Group of Australia, Royal Australian and New Zealand College of Radiologists, Royal College of Surgeons and Cancer Nurses Society of Australia. Invitation emails were sent via these organisations or invitations were included in the organisations' newsletters. Interested healthcare professionals were directed to click on a link to access the training program, work through the website, access the link to the Participant Information and Consent form and then asked to immediately complete the survey. The online survey software Qualtrics was used to administer these surveys.

\section{Measures}

The online survey was adapted from a previously used survey instrument [38] (Supplementary File 1). It included the following measures:

Socio-demographic and professional details. Gender, age, professional background, work setting, length of practice in current field as well as current frequency of discussing genetic testing with patients were assessed.

Experience of using and satisfaction with the online program. Fifteen items with Likert-type and open-ended response options assessed: use of the program; preferences for length of program; satisfaction with different components of the website including: perceived relevance, usefulness and acceptability; and perceived helpfulness of program in terms of improving understanding and skills relating to communicating with breast and ovarian cancer patients about genetic testing. In addition, participants were asked to rate (using Likert-type response options) each of the two modules in terms of whether they were: clearly presented, informative, adequate, appropriate, relevant to their work, and useful to their work.

Self-rated competence in communicating with breast and ovarian cancer patients about genetic testing. Five items, adapted from two previous communication skills training studies [39], assessed self-rated competence in communicating with patients about genetic testing, using Likerttype response options anchored from 'Strongly disagree' to 'Strongly agree' (for example, 'Now that I have completed the training program, I feel confident in communicating with breast and ovarian cancer patients about genetic testing').

\section{Data analysis}

Data were analysed using the Statistical Program for the Social Sciences Version 25. Basic descriptive statistics, including means, medians, percentages, ranges and standard 
deviations were calculated to describe the sample and responses.

\section{Results}

\section{Socio-demographic and professional characteristics}

Thirty-two individuals completed the questionnaire. Demographic and professional characteristics of participants are shown in Table 1 . Fourteen $(44 \%)$ were medical oncologists or medical oncology trainees, $1(3 \%)$ was a gynae-oncologist, 5 (16\%) were surgeons, 11 (34\%) were nurses and $1(3 \%)$ was an oncology pharmacist. Twentyfive $(75 \%)$ were female. Five (16\%) reported never discussing genetic testing with patients, nine (28\%) discussed genetic testing 1-5 times a year, while five (16\%) each discussed it 6 to 10 and 11-20 times a year, and $8(25 \%)>20$ times a year.

\section{Experience of using, and overall satisfaction with, the online program}

All participants completed all sections of the program, and $75 \%$ completed it in one sitting. The time taken to complete the program varied, with three $(9 \%)$ taking $<30 \mathrm{~min}$, eight (25\%) 31-45 min, 14 (44\%) 46-60 min and seven (22\%) 61-90 min. Thirty (94\%) believed that the length of the online training program was about right, and two (6\%) thought it was too short. Fourteen (44\%) were very satisfied, and 17 (53\%) were satisfied with the information contained in the program, while one (3\%) was neither satisfied nor dissatisfied. Similarly, 8 (25\%) of participants reported finding the program "extremely helpful", 19 (59\%) "very helpful" and five (16\%) "satisfactory" in giving them an understanding of issues relating to communicating with breast and ovarian cancer patients about genetic testing. Twenty-nine (91\%) stated that they gained new skills from the program relating to communicating with breast and ovarian cancer patients about genetic testing. Twenty-two (73\%) percent believed that the videos in the program were useful in showing the issues related to genetic testing as experienced by oncology healthcare professionals, while one $(3 \%)$ did not believe so and seven $(23 \%)$ were unsure. Thirty participants $(100 \%$, disregarding two participants where data were missing) considered that the online format was appropriate for the program, that the additional resources contained in the training program were easily accessible, that the program was easy to use, and that they would recommend it to their professional colleagues.
Table 1 Baseline characteristics of oncology healthcare professionals

\begin{tabular}{|c|c|}
\hline Characteristics & $\begin{array}{l}(\mathrm{N}=32) \\
\mathrm{N}(\%)\end{array}$ \\
\hline \multicolumn{2}{|l|}{ Age (years) } \\
\hline $18-29$ & $1(3)$ \\
\hline $30-39$ & $20(62)$ \\
\hline $40-49$ & $9(28)$ \\
\hline $50-59$ & $1(3)$ \\
\hline $60+$ & $1(3)$ \\
\hline \multicolumn{2}{|l|}{ Gender } \\
\hline Female & $24(75)$ \\
\hline Male & $8(25)$ \\
\hline \multicolumn{2}{|l|}{ Professional background } \\
\hline Medical oncologist & $8(25)$ \\
\hline Medical oncologist trainee & $6(19)$ \\
\hline Gynaecological oncologist & $1(3)$ \\
\hline Surgeon & $5(16)$ \\
\hline Nurse & $11(34)$ \\
\hline Oncology pharmacist & $1(3)$ \\
\hline \multicolumn{2}{|l|}{ Place of practice } \\
\hline Metropolitan & $25(78)$ \\
\hline Rural & $5(16)$ \\
\hline Both & $2(6)$ \\
\hline \multicolumn{2}{|l|}{ Public/Private sector practice } \\
\hline Public & $18(56)$ \\
\hline Private & $9(28)$ \\
\hline Both & $5(16)$ \\
\hline \multicolumn{2}{|c|}{ Years of practice in current field } \\
\hline $0-5$ & $21(66)$ \\
\hline $6-10$ & $5(16)$ \\
\hline $11-20$ & $2(6)$ \\
\hline More than 20 & $4(13)$ \\
\hline \multicolumn{2}{|c|}{ How often do you discuss genetic testing with patients? } \\
\hline Never & $5(16)$ \\
\hline $1-5$ times a year & $9(28)$ \\
\hline $6-10$ times a year & $5(16)$ \\
\hline 11-20 times a year & $5(16)$ \\
\hline$>20$ times a year & $8(25)$ \\
\hline
\end{tabular}

\section{Satisfaction with the modules of the online program}

Figure 2 displays the satisfaction with the modules of the online program. Between 70 and $90 \%$ of the participants thought that both modules were "very" clearly presented, informative, appropriate, relevant and useful for participants' work, while between 10 and $33 \%$ provided an endorsement of "somewhat" regarding these attributes. 
Fig. 2 Percentage of participants endorsing modules of training program as "very...

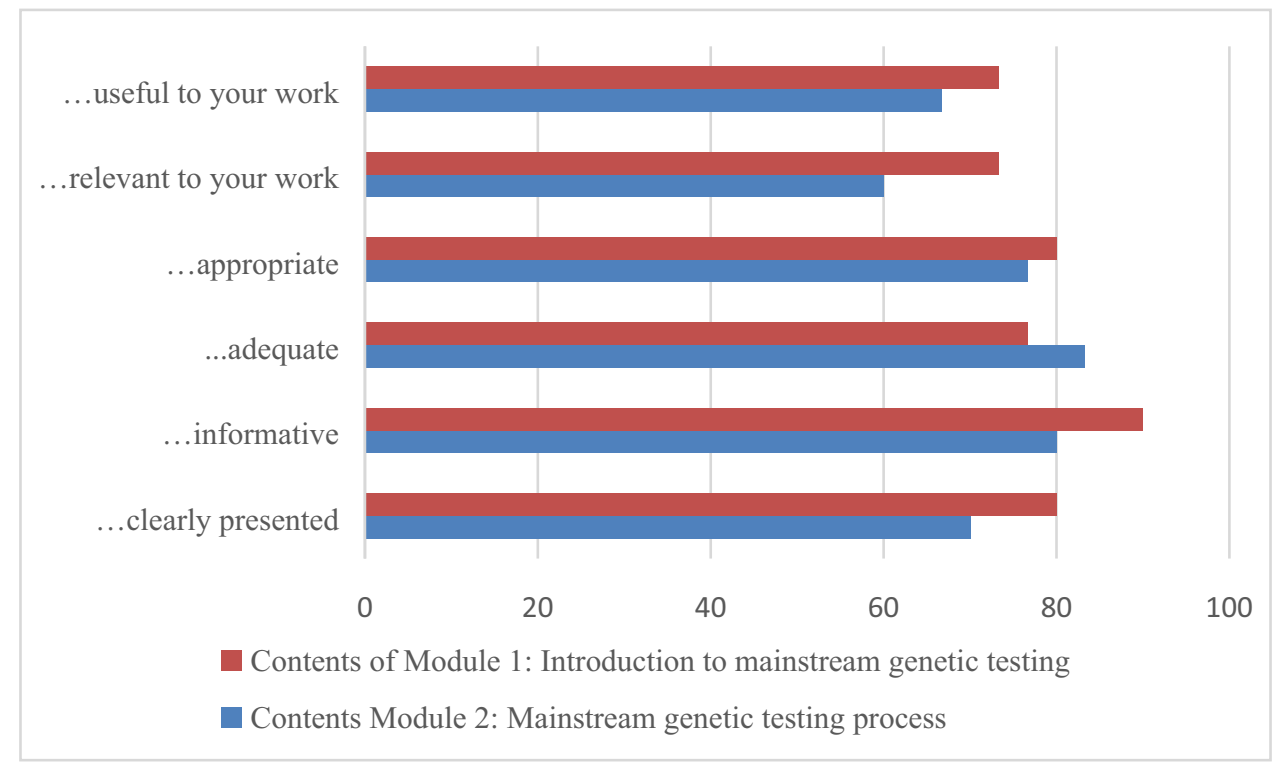

\section{Self-rated competence in communicating with breast and ovarian cancer patients about genetic testing}

Table 2 shows the responses to five items, which assessed self-rated competence in communicating with breast and ovarian cancer patients about genetic testing. For example, $19(61 \%)$ of participants "somewhat agreed" and 10 (32\%) "strongly agreed" they were confident in communicating with breast and ovarian cancer patients about genetic testing after they completed the program, while 2 (7\%) "neither agreed nor disagreed".

\section{Suggestions for improvements}

A number of participants made suggestions for improvements in response to open-ended questions related to several themes: (i) resources (e.g. offer additional links to gain more in-depth knowledge for those who are interested, provide the option of downloading slides or a summary of the training website); (ii) provide more opportunities for clinicians who are time poor (e.g. shorten the videos to enable those who are time poor to watch them); (iii) generalisability (e.g. offer more information about genetic testing in other contexts, for example $B R C A 1 / 2$-positive pancreatic cancer, as well as other inherited conditions and provide training which targets pathogenic variants in genes other than $B R C A 1 / 2$ ); (iv) practice/rehearsal (e.g. provide an opportunity to practice

Table 2 Self-rated competence in communicating with breast and ovarian cancer patients about genetic testing

\begin{tabular}{|c|c|c|c|c|c|}
\hline Statement & $\begin{array}{l}\text { Strongly disagree } \\
\mathrm{n}(\%)\end{array}$ & $\begin{array}{l}\text { Some- } \\
\text { what } \\
\text { disagree } \\
\mathrm{n}(\%)\end{array}$ & $\begin{array}{l}\text { Neither agree } \\
\text { nor disagree } \\
\mathrm{n}(\%)\end{array}$ & $\begin{array}{l}\text { Somewhat agree } \\
\mathrm{n}(\%)\end{array}$ & $\begin{array}{l}\text { Strongly agree } \\
\mathrm{n}(\%)\end{array}$ \\
\hline $\begin{array}{l}\text { Before the training program, I felt confident communicat- } \\
\text { ing with breast and ovarian cancer patients about genetic } \\
\text { testing }\end{array}$ & $3(10)$ & $12(39)$ & $2(6)$ & $11(35)$ & $3(10)$ \\
\hline $\begin{array}{l}\text { Now that I have completed the training programme, I feel } \\
\text { confident in communicating with breast and ovarian cancer } \\
\text { patients about genetic testing }\end{array}$ & $0(0)$ & $0(0)$ & $2(7)$ & $19(61)$ & $10(32)$ \\
\hline $\begin{array}{l}\text { I feel confident that I will use the skills I learned in the train- } \\
\text { ing program }\end{array}$ & $1(3)$ & $0(0)$ & $3(10)$ & $13(42)$ & $14(45)$ \\
\hline $\begin{array}{l}\text { The skills I learned in the training program will allow me to } \\
\text { provide better patient care }\end{array}$ & $0(0)$ & $0(0)$ & $0(0)$ & $15(48)$ & $16(52)$ \\
\hline $\begin{array}{l}\text { The training program prompted me to critically evaluate my } \\
\text { own communication skills in relation to genetic testing }\end{array}$ & $1(3)$ & $4(13)$ & $0(0)$ & $16(52)$ & $10(32)$ \\
\hline
\end{tabular}

Percentages may not add up due to rounding. One participant did not provide responses to any of the items 
Manchester scoring [37]; (v) complex scenarios (e.g. provide information on how to proceed if patients have family members who have already been tested and have been found to be negative, but the family is still at high risk); and (vi) updates (e.g. offer updates to the program to be emailed to people who have completed the program to allow them to keep their knowledge current).

\section{Discussion}

While online training programs have been developed for a range of healthcare professionals in many different healthcare contexts (see [32-34]), we are not aware of any that specifically trained medical specialists in cancer genetics, although Houwink et al. developed and tested a website to train general practitioners in the Netherlands in cancer genetics [7, 40]. Thus, our website fills an important gap in the suite of training resources available for non-genetics healthcare professionals in Australia and is one of the first internationally to specifically focus on mainstreaming of germline testing for cancer genetics.

The current pilot study surveyed predominantly medical oncologists, surgeons and oncology nurses who had completed the program in relation to satisfaction with, and acceptability of, the online program as well as self-rated competence in communicating with breast and ovarian cancer patients about genetic testing following program completion. The majority of participants were satisfied with the information contained in the program, found the program helpful and reported that they had gained new skills from the program relating to communicating with breast and ovarian cancer patients about genetic testing. None reported that the training program was too long, indicating that busy oncology healthcare professionals did not find the time to complete the training onerous. Following completion of the training program, most participants reported that they were confident in communicating with breast and ovarian cancer patients about genetic testing. These findings demonstrate that the online training program was successful in meeting its objectives.

Participants also made a number of suggestions for improvements including providing training about genetic testing in other contexts, for example BRCA1/2-positive pancreatic cancer as well as training which targets pathogenic variants in genes other than $B R C A 1 / 2$. These results indicate that a whole suite of training interventions may be needed to meet oncology healthcare professionals' current needs to cover the increased range of germline testing in different cancers where testing is already being offered. Indeed, when this training website was first developed, the intention was to be able to modify it and add more modules to it, as more cancers could be tested under the Medicare Benefits
Scheme in the future, e.g. colorectal cancers. A web portal with a wide range of different modules for users to choose from may be ideally suited to meet healthcare professionals' needs. A core module with generic content might be presented, together with specific modules that address diseasespecific issues. This approach has been shown to work well in other contexts [41]. The current website and its evaluation will provide some guidance as to the possible contents of individual modules comprising such web portals. Other suggestions for improvements made by participants included emailing updates to the program to people who have completed the program to allow them to keep their knowledge current. Other options for updating may include regular webinars, where those who have previously completed the training program are invited.

During the COVID-19 pandemic, online teaching has become more common and acceptable due to restrictions on travel and conference attendance [42,43]. It provides a cost-effective strategy for dissemination of new knowledge and skills training that ensures healthcare professional safety. Another approach has been to use videos in a webinar or have an actor playing the role of the patient in webinars for interactions to be practiced, rather than "live" at a central venue. This program could be adapted to such an approach. As genetic testing results may also be delivered via telehealth, this approach allows participants to learn how to use this medium effectively.

About one quarter of participants did either not believe that the videos in the program were useful or were unsure. The videos featured experts in cancer genetics, rather than professional actors, reflecting the low budget we had available. It is possible that more sophisticated videos, e.g. professionally produced videos featuring actors to play the role of patients and healthcare professionals to engage users in experiential learning activities, might have resulted in higher participant satisfaction. We have recently demonstrated that an online training website with video-based patient vignettes using professional actors can be used successfully to show exemplary clinician behaviours in the context of communication skills training in oncology [38]. Similar videos could be produced for training in cancer genetics, and such videos could be adapted for use in "live" webinars and training with actors. The recent Australian survey of medical specialists regarding their continuing education needs relating to genomic medicine shows that participants believed that experiential learning in genomic medicine was necessary to develop the confidence and skills needed for clinical care [22]. Hence, an important aim of future research should be to develop communication skills training programs specific to cancer genetics incorporating experiential learning activities. Such learning activities could incorporate watching videos and practicing with peers. Studies using similar experiential learning have demonstrated that communication skills 
training of oncologists increases the number of observable communication skills utilised by specialists in both simulated and actual consultations following training [44, 45].

The limitations of this study should be mentioned. First, it is unknown how many participants received the invitation to the study, and therefore it is not possible to report the response rate and assess participation bias. Oncology healthcare professionals were asked whether they had gained new skills from the program; however, this question should have been asked differently given they have not yet had an opportunity to use these new skills in practice. A follow-up assessment (e.g. six months after completion of the modules) would have been helpful to assess whether there was a gain in skills. Participants were asked to self-rate competence, and we did not objectively measure competence. Future studies should record consultations involving patients to demonstrate actual increases in the quality of communication and include direct assessments of patient outcomes as well as measurements against published competencies [46]. Another limitation was that the modules were restricted to genetic testing in the BRCA1/2 genes and did not include testing of other breast and ovarian cancer genes. Given the promising results from this pilot study, future studies should include randomised trials to evaluate whether the program changes clinical practice and improves patient outcomes. Future studies should also assess whether the online program actually leads to an increase in the use of genetic testing. Moreover, future studies should compare the effects of online training to blended models that combine some faceto-face with online learning.

Supplementary Information The online version contains supplementary material available at https://doi.org/10.1007/s10689-021-00261-1.

Acknowledgements We are thankful to all participants for giving their time to complete the evaluation. The development of the training website was funded by AstraZeneca, and the pilot study was funded by the Translational Cancer Research Network, Cancer Institute New South Wales. Bettina Meiser was supported by a Senior Research Fellowship Level B (ID 1078523) from the National Health and Medical Research Council (NHMRC) of Australia. Paula Woodward was supported by funding from AstraZeneca to develop the training website. Phyllis Butow was funded by an NHMRC Senior Principal Research Fellowship. Megan Best was funded by a Cancer Institute New South Wales Early Career Fellowship. Frances Boyle is supported by the friends of the Mater Foundation. Katy Bell was supported by an Investigator Grant (ID 1174523) from the National Health and Medical Research Council (NHMRC) of Australia.

Author contributions BM: conceptualization, methodology, formal analysis, investigation, writing original draft, writing - review \& editing, funding acquisition. PW: conceptualization, methodology, writing-review \& editing, funding acquisition. MG: conceptualization, methodology, writing-review \& editing. MK: conceptualization, methodology, writing - review \& editing. HMF: conceptualization, methodology, writing - review \& editing. YA: conceptualization, methodology, writing - review \& editing. PB: conceptualization, methodology, writing-review \& editing. FB: conceptualization, methodology, writing-review \& editing. MB: conceptualization, methodology, writing-review \& editing. NT: conceptualization, methodology, writing-review \& editing. KB: conceptualization, methodology, writingreview \& editing. writing - review \& editing. KT: conceptualization, methodology, writing-review \& editing.

Data availability Data will be made available upon reasonable request.

\section{Declarations}

Conflict of interest Margaret Gleeson and Maira Kentwell declare remunerated consultant roles with the company AstraZeneca with respect to activities unrelated to this article. Paula Woodward had a remunerated consultant role with respect to the current study. The other authors declare that they have no conflicts of interest.

Ethical approval This study was approved by the University of New South Wales (UNSW) Human Research Ethics Advisory Panel (Biomedical), approval number 180586.

Consent to participate Informed consent was sought from all research participants.

\section{References}

1. Moore K, Colombo N, Scambia G et al (2018) Maintenance olaparib in patients with newly diagnosed advanced ovarian cancer. $\mathrm{N}$ Engl J Med 379:2495-2505. https://doi.org/10.1056/NEJMoa1810 858

2. Puiade-Lauraine E, Ledermann J, Selle F et al (2017) Olaparib tablets as maintenance therapy in patients with platinum- sensitive, relapsed ovarian cancer and A BRCA1/2 mutation (SOLO2/ ENGOT-Ov21): a double-blind, randomised, placebo-controlled, phase 3 trial. Lancet 8(9):1274-1284. https://doi.org/10.1016/ S1470-2045(17)30469-2

3. Mirza M, Monk B, Herrstedt J et al (2016) Niraparib maintenance therapy in platinum-sensitive, recurrent ovarian cancer. N Engl J Med 375:2154-2164. https://doi.org/10.1056/NEJMoa1611310

4. Hartmann LC, Schaid DJ, Woods JE et al (1999) Efficacy of bilateral prophylactic mastectomy in women with a family history of breast cancer. N Engl J Med 340(2):77-84. https://doi.org/10. 1056/NEJM199901143400201

5. Evans D, Ingham S, Baildam A et al (2013) Contralateral mastectomy improves survival in women with BRCA1/2-associated breast cancer. Breast Cancer Res Treat 140(1):135-142. https:// doi.org/10.1007/s10549-013-2583-1

6. Rebbeck TR, Friebel T, Lynch HT et al (2004) Bilateral prophylactic mastectomy reduces breast cancer risk in BRCA1 and BRCA2 mutation carriers: the PROSE Study Group [see comment]. J Clin Oncol 22(6):1055-1062. https://doi.org/10.1200/ JCO.2004.04.188

7. George A, Riddell D, Seal S et al (2016) Implementing rapid, robust, cost-effective, patient-centred, routine genetic testing in ovarian cancer patients. Sci Report 6:29506. https://doi.org/10. 1038/srep29506

8. Kentwell M, Dow E, Antill Y et al (2017) Mainstreaming cancer genetics: a model integrating germline BRCA testing into routine ovarian cancer clinics. Gynecol Oncol 145:130-136. https://doi. org/10.1016/j.ygyno.2017.01.030

9. Cancer Institute New South Wales (2021) BRCA1 and BRCA2 genetic testing. https://www.eviq.org.au. Accessed 1 Feb 2021 
10. National Institute for Health and Care Excellence, United Kingdom (2013) Familial breast cancer: classification and care of people at risk of familial breast cancer and management of breast cancer and related risks in people with a family history of breast cancer

11. Meiser B, Tucker K, Friedlander M et al (2008) Genetic counselling and testing for inherited gene mutations in newly diagnosed patients with breast cancer: a review of the existing literature and a proposed research agenda. Breast Canc Res 10:216

12. Trainer A, Lewis C, Tucker K, Meiser B, Friedlander M, Ward R (2010) Treatment-focused genetic assessment in breast cancerthe evolving role of the familial cancer services. Nat Rev Clin Oncol 7:708-717

13. Department of Health AG (2021) Medicare benefits schedule. http://www9.health.gov.au/mbs/fullDisplay.cfm?type=item\&q= $73295 \&$ qt=item. Accessed 3 Feb 2021

14. Tung N, Garber J (2018) BRCA1/2 testing: therapeutic implications for breast cancer management. Br J Cancer 119(2):141-152. https://doi.org/10.1038/s41416-018-0127-5

15. Aronson N (2015) Making personalized medicine more affordable. Ann N Y Acad Sci 1346(1):81-89. https://doi.org/10.1111/ nyas. 12614

16. Department of Health AG (2021) Medicare benefits schedule. http://www9.health.gov.au/mbs/fullDisplay.cfm?type=item\&q= 73296\&qt=ItemID. Accessed 3 Feb 2021

17. Chow-White P, Ha D, Laskin J (2017) Knowledge, attitudes, and values among physicians working with clinical genomics: a survey of medical oncologists. Human Resourc Health 15:42. https://doi. org/10.1186/s12960-017-0218-Z

18. Douma K, Smets E, Allain D (2016) Non-genetic health professionals' attitude towards, knowledge of and skills in discussing and ordering genetic testing for hereditary cancer. Fam Cancer 15(2):341-350. https://doi.org/10.1007/s10689-015-9852-6

19. Giardello FM, Brensinger JD, Petersen GM et al (1997) The use and interpretation of commercial APC gene testing for familial adenomatous polyposis. N Engl J Med 336:823-827. https://doi. org/10.1056/NEJM199703203361202

20. Wideroff L, Vadaparampil S, Greene M, Taplin S, Olson L, Freedman A (2005) Hereditary breast/ovarian cancer and colorectal cancer genetics knowledge in a national sample of US physicians. J Med Genet 42(10):749-755. https://doi.org/10.1136/jmg.2004. 030296

21. Dung Ha V, Frizzo-Barker J, Chow-White P (2018) Adopting clinical genomics: a systematic review of genomic literacy among physicians in cancer care. BMC Med Genom 11:18. https://doi. org/10.1186/s12920-018-0337-y

22. McClaren M, Crellin E, Janinski M et al (2020) Preparing medical specialists for genomic medicine: continuing education should include opportunities for experiential learning. Front Genet 11:151. https://doi.org/10.3389/fgene.2020.00151

23. Christianson C, Potter Powell K, Estabrooks Hahn S et al (2012) The use of a family history risk assessment tool within a community health care system: views of primary care providers. J Genet Couns 21(5):652-661. https://doi.org/10.1007/s10897-011-9479-1

24. Flynn B, Wood M, Ashikaga T, Stockdale A, Dana G, Naud S (2010) Research article primary care physicians' use of family history for cancer risk assessment. BMC Fam Pract 11:45. https:// doi.org/10.1186/1471-2296-11-45

25. Vadaparampil S, Scherr C, Cragun D, Malo T, Pal T (2015) Pretest genetic counseling services for hereditary breast and ovarian cancer delivered by non-genetics professionals in the state of Florida. Clin Genet 87:473-477. https://doi.org/10.1111/cge. 12405

26. Meiser B, Gleeson M, Kasparian N et al (2012) There is no decision to make: experiences and attitudes toward treatment-focused genetic testing among women diagnosed with ovarian cancer. Gynecological Oncology 124:153-157

27. Meiser B, Gleeson M, Watts K et al (2012) Getting to the point: what women newly diagnosed with breast cancer want to know about treatment-focused genetic testing. Oncol Nurs Forum 39(2):E101-E129. https://doi.org/10.1188/12.ONF.E101-E111

28. Gleeson M, Meiser B, Barlow-Stewart K, Trainer A, Friedlander M, Kasparian N (2013) What women want: communication and information needs of women newly diagnosed with ovarian cancer regarding treatment focused genetic testing. Oncol Nurs Forum 40(3):275-283. https://doi.org/10.1188/13.ONF.40-03AP

29. Zilliacus E, Meiser B, Gleeson M et al (2012) Are we being overly cautious? A qualitative inquiry into the experiences and perceptions of treatment-focussed genetic testing for women recently diagnosed with breast cancer. Suppl Care Cancer 21(11):2949-2958

30. Department of Health (2018) Implementation Plan-National Health Genomics Policy. https://www1.health.gov.au. Accessed 3 Mar 2021. Canberra, Australia

31. National Health and Medical Research Council (2015) Principles for the translation of 'omics'-based tests from discovery to health care. Canberra, Australia

32. Cook D, Levinson A, Garside S et al (2008) Internet-based learning in the health professions: a meta-analysis. JAMA 300(10):1181-1196. https://doi.org/10.1001/jama.300.10.1181

33. Wutoh R, Boren S, Balas E (2004) eLearning: a review of Internet-based continuing medical education. J Contin Educ Health Prof 24(1):20-30. https://doi.org/10.1002/chp.1340240105

34. Hammoud M, Gruppen L, Erickson S et al (2006) To the point: reviews in medical education online computer assisted instruction materials. Am J Obstet Gynecol 194(4):1064-1069. https://doi. org/10.1016/j.ajog.2005.08.023

35. Gleeson M, Kentwell M, Meiser B et al (2020) The development and evaluation of a nationwide training program for oncology health professionals in the provision of genetic testing for ovarian cancer patients. Gynecologic Cancer 158:431-439. https://doi.org/ 10.1016/j.ygyno.2020.05.001

36. Quinn V, Meiser B, Kirk J et al (2017) Streamlined education is effective for women newly diagnosed with breast cancer considering genetic testing. Genet Med 19(4):448-456. https://doi.org/10. 1038/gim.2016.13

37. Evans D, Harkness E, Plaskocinska I et al (2017) Pathology update to the Manchester scoring system based on testing in over 4000 families. J Med Genet 54(10):674-681. https://doi.org/10. 1136/jmedgenet-2017-104584

38. Kaur R, Meiser B, Zilliacus E et al (2019) Evaluation of an online communication skills training programme for oncology health care professionals working with culturally and linguistically diverse patients. Supp Care Canc 27(5):1951-1960

39. Fallowfield L, Lipkin M, Hall A (1998) Teaching senior oncologists communication skills: results from phase I of a comprehensive longitudinal program in the United Kingdom. J Clin Oncol 16(5):1961-1968. https://doi.org/10.1200/JCO.1998.16.5.1961

40. Houwink E, van Teeffelen S, Muijtjens A et al (2014) Sustained effects of online genetics education: a randomized controlled trial on oncogenetics. Eur J Hum Genet 22:310-316. https://doi.org/ 10.1038/ejhg.2013.163

41. Menrath I, Ernst G, Lange K et al (2019) Evaluation of a generic patient education program in children with different chronic conditions. Health Educ Res 34(1):50-61. https://doi.org/10.1093/ her/cyy045

42. de Las HB, Saini K, Boyle F et al (2020) Cancer treatment and research during the COVID-19 pandemic: experience of the first 6 months. Oncol Ther 8(2):171-182. https://doi.org/10.1007/ s40487-020-00124-2 
43. Gordon M, Patricio M, Horne L et al (2020) Developments in medical education in response to the COVID-19 pandemic: a rapid BEME systematic review: BEME Guide No. 63. Med Teach 42(11):1202-1215. https://doi.org/10.1080/0142159X.2020. 1807484

44. Fallowfield L, Jenkins V, Farewell V, Saul J, Duffy A, Eves R (2002) Efficacy of a Cancer Research UK communication skills training model for oncologists: a randomised controlled trial. Lancet 359(9307):650-656. https://doi.org/10.1016/S0140-6736(02) 07810-8

45. Butow P, Cockburn J, Girgis A et al (2008) Increasing oncologists' skills in eliciting and responding to emotional cues: evaluation of a communication skills training program. Psycho-Oncol 17(3):209-218. https://doi.org/10.1002/pon.1217

46. Human Genetics Society of Australia. https://www.hgsa.org.au/ documents/item/10550, 2021 AM (2019) Competency Standards for Genetic Counsellors

Publisher's Note Springer Nature remains neutral with regard to jurisdictional claims in published maps and institutional affiliations.

\section{Authors and Affiliations}

\section{Bettina Meiser ${ }^{1}$ - Paula Woodward ${ }^{2} \cdot$ Margaret Gleeson $^{3} \cdot$ Maira Kentwell $^{4} \cdot$ Helen Mar Fan $^{5} \cdot$ Yoland Antill $^{6,7}$. Phyllis N. Butow ${ }^{8} \cdot$ Frances Boyle $^{9,10} \cdot$ Megan Best $^{11} \cdot$ Natalie Taylor $^{12,13} \cdot$ Katy Bell $^{14} \cdot$ Kathy Tucker $^{15}$}

1 Psychosocial Research Group, Prince of Wales Clinical School, University of New South Wales (UNSW), Level 4, C25 Lowy Building, Sydney, NSW 2052, Australia

2 The Med Collective Pty Ltd, Sydney, Australia

3 Hunter Family Cancer Service, Newcastle, Australia

4 Parkville Familial Cancer Clinic, Peter MacCallum Cancer Centre and Royal Melbourne Hospital, Melbourne, Australia

5 Genetic Health Queensland, Royal Brisbane and Women's Hospital, Brisbane, Australia

6 Parkville Familial Cancer Clinic, Peter MacCallum Cancer Centre, Melbourne, Australia

7 Family Cancer Clinic, Monash Health, Nursing and Health Sciences, Faculty of Medicine, Nursing and Health Sciences, Monash University, Melbourne, Australia

8 Psycho-Oncology Co-Operative Research Group, Centre for Medical Psychology and Evidence-Based Decision-Making, The University of Sydney, Sydney, Australia
9 School of Medicine, University of Sydney, Sydney, Australia

10 Pam McLean Centre, Faculty of Medicine and Health, University of Sydney, Sydney, Australia

11 Institute for Ethics and Society, University of Notre Dame, Sydney, Australia

12 Cancer Research Division, Cancer Council of New South Wales, Sydney, Australia

13 Faculty of Health Sciences, University of Sydney, Sydney, Australia

14 School of Public Health, The University of Sydney, Sydney, Australia

15 Hereditary Cancer Clinic, Prince of Wales Hospital and Prince of Wales Clinical School, UNSW Sydney, Sydney, Australia 